\title{
Yönetim Çalışmalarında Kullanılan Ulusal Kültür Modellerinin Karşılaştırılması
}

\author{
Onur DİRLIK*
}

ÖZ

$\mathrm{Bu}$ çalışmanın amacı ulusal kültür modeli teorileri arasında ön plana çıkan Hofstede, Hampden-Turner ve Trompenaars ve Schwartz tarafindan ortaya koyulan kültür modellerini derinlemesine incelemek ve bu modellerin üstün ve zayıf yanlarını tartışmaktır. Modellerin ve yöneltilen eleştirilerin incelenmesi, üç farklı kültür modelinin karşılaştırmaları yapılarak gerçekleştirilmiştir. Bu sayede, özellikle yönetim çalışmalarında son yıllarda önem kazanan ulusal farklılıkların ve benzerliklerin anlaşılmasına yönelik olarak yapılan çalışmalara kuramsal bir düşünme alanı yaratılmak istenmektedir. Çalışmada modeller analiz düzeyleri, amprik/teorik destek, analiz teknikleri ve değişimi açıklama potansiyeli boyutları üzerinden karşılaştırılmıştır. Yapılan inceleme sonucunda okuyuculara modellerin hangi alanlarda gelişime ve katkıya ihtiyaç duyduğuna yönelik olarak bir ajanda oluşturulmuştur.

Anahtar Kelimeler: Hofstede Kültür Modeli, Hampden-Turner ve Trompenaars Kültür Modeli, Schwartz Kültür Modeli, Ulusal Kültür Modelleri, Farklı Kültürlerde Yönetim

JEL Sinıflandırması: Z10, M14

\section{Comparison of National Cultural Models Used in Management Studies}

\begin{abstract}
The aim of this study is to examine the cultural models put forward by Hofstede, Hampden-Turner and Trompenaars, and Schwartz, which are prominent among the national culture model theories, and to discuss the strengths and weaknesses of these models. The examination of the models and the criticisms were made by comparing three different cultural models. In this way, it is desired to create a theoretical thinking area for the studies carried out to understand the national differences and similarities, which have gained importance in recent years, especially in management studies. In the study, models were compared in terms of levels of analysis, empirical/theoretical background, analysis techniques, and potential to explain the change. As a result of the examination, an agenda was created for the readers in which areas the models needed improvement and contribution.
\end{abstract}

Keywords: Hofstede Cultural Model, Hampden-Turner and Trompenaars Cultural Model, Schwartz Cultural Model, National Culture Models, Cross-Cultural Management

JEL Classification: Z10, M14

Geliş Tarihi / Received: 31.10.2021 Kabul Tarihi / Accepted: 15.12.2021 Doi: 10.17541/optimum.1017014

\footnotetext{
* Dr. Öğr. Üyesi, Eskişehir Osmangazi Üniversitesi, İktisadi ve İdari Bilimler Fakültesi, İşletme Bölümü, onur@ogu.edu.tr, ORCID: 0000-0002-7045-0774
} 


\section{GİRIŞ}

Değerler, bir ulusun üyelerini bir arada tutan ve diğer kültürlerdeki değerlere bakış açısını şekillendiren önemli kültür boyutlarıdır. Bireylerin farklı kültürlere karşı yaklaşımlarını ortaya koyma açısından ulusal kültürlerdeki farklılıkların incelenmesi önemlidir. Küreselleşme ekonomik, sosyo-kültürel, siyasi, teknolojik açılardan dünya üzerindeki ülkeleri, toplumları, örgütleri ve insanları giderek önemi artan bir şekilde etkilemeye devam etmesi ulusal kültürlerdeki farklılıklara yönelik araştırmaları daha da önemli hale getirmiştir. Ulusal kültürlerin farklı boyutları, aynı zamanda örgüt çalışmalarının pek çok alanı ile de ilgilidir. Ulusal ve uluslar arası yönetim açısından gerçekleştirilen pek çok uygulama içerisinde - insan kaynakları yönetimi, istihdam süreci ve ücret politikaları, büyüme stratejileri, girişimcilik, pazarlama stratejileri, finans yönetimi vb. - ulusal kültürlerdeki farklılıklar ve uluslararası şirketlerde farklı kültürel geçmişlere ve değerlere sahip çalışanların yarattığı çalışma ortamı önem kazanmıştır.

Ulusal ve örgütsel kültür üzerine birçok ufuk açıcı çalışmanın altında yatan tez, farklı ülkelerdeki örgütlerin çalışma değerleri, inançları ve yönelimlerinde milliyetten etkilenen farklılıkların olduğudur. Örgütlerin kültürü ve kültürün örgütlerin davranışlarını nasıl etkilediğine ilişkin söylemler genellikle karmaşıktır. Bu alanda tek bir model yerine birçok kültür modeli ortaya atılmıştır (Bhaskaran ve Sukumaran, 2007). Kültürün anlaşılması zor olan doğası nedeni ile birey davranışı üzerindeki direk etkisini ortaya koymakta kolay olmamaktadır. Ulusal kültür düzeyindeki değerleri ve bunların davranışlar üzerindeki etkisini inceleyen çeşitli teorik yaklaşımlar ve kültür modeli bulunmaktadır. Bu kültür modellerinin çeşitliliği yüksek olmakla birlikte bazıları çeşitli araştırma kurumları tarafından gerçekleştirilmiş bazıları ise akademisyenlerin katkısı ile oluşturulmuştur. Örgüt ve yönetim çalışmalarında kullanılan temel çalışmaları Kluckhon ve Stdrotbeck'in değer yönelimi modeli (1961), GLOBE kültürel boyutlar araştırması (globeproject.com), Dünya değerler araştırması (worldvaluessurvey.org), Hall'ın yüksek ve düşük bağlamlı toplumlar araştırması (1959), Laurent'in yönetici rolleri çalışması (1983), Ronen-Shenkar Kültür Sınıflandırması (1985), Herskovits Kültür Sınıflandırması (1949), Lewis Kültür Sınıflandırması (2006) gibi sıralamak mümkündür. Bahsi geçen bu çalışmalar alandaki çeşitliliği göstermekle birlikte en yaygın olarak karşımıza çıkanlardır. Alanda yer alan bu çeşitliliğin getirdiği yaratıcılık ve kültürleri açıklama potansiyelinin artması gibi avantajlı yanlarının yanında, farklı yaklaşımların bulunması kafa karşıklığına da neden olabilmektedir. Özellikle son y1llarda yaşanan küresel düzeydeki pandemi ile birlikte global tedarik zinciri yeniden sorgulanmaya başlanmış, uluslararası işletmecilik çalışmalarında kültür gibi ülkeleri anlamaya yarayan çalışmalar yeniden popüler olmaya başlamıştır. Bu çalışma da alandaki çeşitliliğin avantajlı yönlerini kabul etmekle birlikte, bu alanda en çok kullanılan üç modelin benzerlikleri ve farklılıkları tartışılarak okuyucuya bir ajanda oluşturulmaya çalışılacaktır.

Çalışmanın böyle bir fikirle ortaya çıkmasındaki temel motivasyon yerli hatta yabancı literatürde oldukça popüler olan kültür çalışmalarına rağmen, çok kullanılan belli başlı modelleri bir arada toparlayarak karşılaştıran çalışmanın bulunmamasıdır. Çalışmanın temel amacı özellikle karşılaştırmalı kültür çalışması yapacak araştırmacılara seçecekleri kuramsal altyapı hakkında bir çıkış noktası sunmak ve modellerin birbirlerine göre üstün ve zayıf yönleri hakkında fikir sahibi olunmasını sağlamaktır. Bu amaçla çalışmada zaman zaman kültür çalışmalarının doğasına ve yöntem tartışmalarına da göndermeler yapılarak okuyucuların bu alanda halen tartışmalı olan konularda da dikkatinin çekilmesi amaçlanmaktadır.

Bu kapsamda çalışmada örgüt çalışmalarında en sık kullanıldığı tespit edilerek seçilen (Brewer ve Venaik, 2012, Bhaskaran ve Sukumaran, 2007, López-Duarte, vd., 2016) Hofstede, Hampden-Turner ve Trompenaars ve Schwartz tarafindan ortaya koyulan kültür modelleri ele alınmıştır. $\mathrm{Bu}$ araştırmalara yöneltilen eleştiriler incelenmiş, üç farklı kültür modeli karşılaştırması yapılarak bunun sonucunda elde edilen yorumlar ortaya koyulmuştur. Buna göre 
modeller uygulanabilir analiz düzeyleri analiz teknikleri, amprik/teorik destek, değişimi açıklama potansiyeli boyutları üzerinden karşılaştırılmıştır.

\section{2. ÜC BÜYÜK KÜLTÜR MODELİ}

\subsection{Hofstede'in Değer Boyutları}

Hollandalı yönetim araştırmacısı Geert Hofstede $(1980,2001)$ örgüt literatüründe en yaygın kullanıma sahip kültürel farklılıklar modelini geliştirmiştir. Hofstede'in modeli büyük çok uluslu bir şirketin çeşitli ülkelerden çalışanları üzerinde yapılan bir araştırma sonucunda ortaya çıkmış ve bu çalışma farklı kültürlerin nelere değer verdikleri konusundaki farklılıklarına göre ayırt edilebileceğine dayanmıştır. Bazı kültürler, bireyler arasındaki eşitliğe büyük önem verirken diğerleri bireyler arasındaki hiyerarşi ve güç mesafesine önem vermektedirler. Benzer bir şekilde, bazı kültürler günlük yaşamlarında kesinliğe önem vermekte ve beklenmeyen olaylar ile başa çıkma konusunda zorluk yaşamakta, diğerleri ise belirsizliğe büyük tolerans gösterebilmekte ve değişimden zevk duymaktadırlar. Bu değer boyutlarına dayanarak Hofstede, kültürler arasında örgütsel davranış konusunda önemli bir bakış açısı kazanılabileceğini savunmuştur. Hofstede, başlangıçta dört boyut ile daha sonra Michael Bond (1991) ile yaptıkları araştırma sonrasında ilave edilen beşinci bir boyut ile kültürlerin sınıflandırılabileceğini ortaya koymuştur. Daha sonra modele son boyut olan altıncı boyutta eklenerek nihai halini almıştır. Hofstede ve ekibi modelin nihai halinin yaygınlaşması ve ülkeler arasındaki karşılaştırılmanın yapılmasının kolaylaştırılması için online bir veri seti oluşturmuştur (bknz. hofstedeinsights.com). Bu boyutlar şu şekilde özetlenebilir:

Güç Mesafesi: Toplumda gücün uygun bir şekilde dağılımı konusundaki düşünceleri ifade etmektedir. Düşük güç mesafesi, etkili liderlerin kendilerine bağlı olanlara kıyasla önemli ölçüde güce sahip olmaları gerekmediği düşüncesine sahip toplumlarda görülmektedir. Avusturya, İsrail, Danimarka, İrlanda, Norveç, İsveç gibi ülkeler düşük güç mesafesine sahip ülkelere örnek olarak gösterilebilir. Yüksek güç mesafesi, otorite sahibi kişilerin kendilerine tabi olanlara göre önemli bir güce sahip olmaları gerektiği düşüncesine sahip toplumların bir özelliğidir. Malezya, Meksika, Suudi Arabistan yüksek güç mesafesine sahip ülkelere örnek olarak gösterilebilir (Nardon ve Steers, 2009, 2). Güç mesafesi, toplum üyelerinin daha az ve daha çok güce sahip olanlarının davranışlarını etkilemektedir. Yüksek güç mesafesine sahip toplumlar, güç eşitsizliklerinin daha fazla meşrulaştırılmasına ihtiyaç duyulmadığ 1 , herkesin bir yeri olduğu hiyerarşik bir düzeni kabul etmektedirler (Chanchani ve Theivanathampillai, 2009: 5). Bir toplumun eşitsizlik düzeyinin liderler kadar takipçiler tarafından da onaylandığını bilinmektedir. Güç ve eşitsizlik, elbette, herhangi bir toplumun son derece temel gerçekleridir. Tüm toplumlar eşit değildir, ancak bazıları diğerlerinden daha eşitsizdir (Hofstede, 2011).

Belirsizlikten Kaçınma: Tolerans gösterilebilecek belirsizlik boyutunu ve onun kural koyma üzerindeki etkisini ifade etmektedir. Düşük belirsizlikten kaçınma düzeyi, belirsizlik konusundaki toleransa ve belirsizliği sınırlandırmak için ihtiyaç duyulan kuralların azlığına işaret etmektedir. Singapur, Jamaika, Danimarka, İsveç, İngiltere örnek ülkeler olarak gösterilebilir. Yüksek belirsizlikten kaçınma düzeyi, belirsizlik konusunda tolerans gösterilmemesi ve belirsizliği engellemek için oluşturulan pek çok kuraların varlığını ifade etmektedir. Yunanistan, Portekiz, Uruguay, Japonya, Fransa, İspanya gibi ülkeler yüksek belirsizlikten kaçınma düzeyine sahip ülkeler arasında sayılabilir (Nardon ve Steers, 2009: 2). Yüksek belirsizlikten kaçınma düzeyine sahip toplumlar, kesinlik ve uyumluluğu teşvik etmek ve korumak için katı davranış ve düşünce kodlarına sahiptirler. Bu toplumlar, normalin dışına çıkan kişilere ve düşüncelerine tolerans göstermemektedirler. Düşük belirsizlikten kaçınma düzeyine sahip toplumlar, daha rahat bir atmosfere sahiptir ve normalin dışına çıkma durumuna daha kolay tolerans göstermektedirler. Belirsizlikten kaçınma, bireylerin kuruluşlarını ve 
örgütlerini oluşturma yolları için sonuçlar teşkil etmektedir (Chanchani ve Theivanathampillai, 2009: 5).

Bireycilik - Toplulukçuluk: Birey ya da grup ihtiyaçlarına verilen göreceli önemi ifade etmektedir. Toplulukçuluk, grup ihtiyaçlarının genellikle bireyin ihtiyaçlarının önüne geçtiği toplumlarda görülmektedir. Japonya, Kore, Endonezya, Pakistan, Latin Amerika toplulukçuluğa önem veren ülkelere örnek gösterilebilir. Bireycilik, birey ihtiyaçlarının genellikle grup ihtiyaçlarından önce geldiği toplumlar için geçerlidir. ABD, Avustralya, İngiltere, Hollanda, İtayla, İskandinavya buna örnek ülkelerdir (Nardon ve Steers, 2009: 2). Diğer bir ifade ile bireycilik, bireylerin yalnızca kendilerine ve kendi yakın aile bireylerine önem verdikleri gevşek sosyal yapıların tercih edildiği toplumlardır. Toplulukçuluk ise bireylerin sorgulanmayan bir sadakat karşısında akrabalarının, ait oldukları zümrenin ya da diğer grup içinde yer alan kişilerin kendilerini gözetmelerini bekledikleri daha sıkı sosyal yapıların tercih edildiği toplumlar olarak ifade edilebilir (Chanchani ve Theivanathampillai, 2009: 4). Bireyci toplumlarda bireyler sadece kendilerine ve yakın ailelerine bakarlar, oysa kolektivist kültürlerde bireyler sadakat karşılı̆̆ında kendilerine bakan gruplara aittir (Soares, vd., 2007).

Erillik - Dişillik: İddiacıllğa karşı boyun eğme, maddeci zenginliğe karşı yaşam kalitesine önem verme olarak ifade edilebilir. Eril toplumlarda maddeci zenginlik, para, kişisel amaçlar peşinde koşma ön plandadır. Japonya, Avusturya, İtayla, İsviçre, Meksika bu ülkeler arasında gösterilmiştir. Dişil toplumlarda ise güçlü sosyal bağlantılar, yaşam kalitesi ve diğerlerinin refahı öne çıkmaktadır. İsveç, Norveç, Hollanda, Kosta Rika bu ülkelere önek verilebilir (Nardon ve Steers, 2009: 2).

Erillik karşıtı olan dişil, cinsiyetler arasındaki rollerin dağılımını ifade eder. İddialı olan değerlere 'eril' ve mütevazı, şefkatli temellere sahip değerlere 'dişil' adı verilir. Dişil değerlere sahip ülkelerdeki kadınlar, erkeklerle aynı mütevazı, sevecen değerlere sahiptir. Eril değerlere sahip ülkelerde ise biraz iddialı ve rekabetçidirler; ancak yine de erkekler kadar değildir (Hofstede, 2003).

Uzun Vadeli yönelimler - Kısa Vadeli Yönelimler: Yaşam, iş ve ilişkiler konusundaki görünümü ifade etmektedir. Kısa vadeli yönelimler, geçmiş ve şimdiki zamanı ifade etmektedir. Sosyal sorumluluklar ve gelenekler ön plandadır. Pakistan, Nijerya, Filipinler, Rusya kısa vadeli yönelimlere sahip ülkeler olarak gösterilmiştir. Uzun vadeli yönelimler geleceğe yönelik olma anlamına gelmektedir. Kendini adama, çok çalı̧̧ma, verimlilik ön plandadır. Çin, Kore, Japonya ve Brezilya örnek ülkelerdir (Nardon ve Steers, 2009: 2). Bu boyutun hem olumlu hem de olumsuz olarak derecelendirilen değerleri Konfüçyüs'ün öğretilerinde bulunur, ancak boyut, örneğin Brezilya gibi Konfüçyüs mirası olmayan ülkeler için de geçerlidir. Çok kolektivist Güneydoğu Asya ülkelerinde olduğu gibi, uzun vadeli yönelim kolektivizm ile ilişkilendirilmek zorunda değildir. Avrupa içinde Finlandiya ve Hollanda oldukça uzun vadeli, İsveç ve Almanya ise daha kısa vadelidir. Çin, Japon, Kore ve Vietnam kültürü uzun vadelidir (Hofstede, 2008).

Hoşgörü ve Kısıtlama: Bu boyut çalışmaya 2010 yılında eklenmiştir. Dünya değerler araştırmasının boyutun eklenmesinde etkisi vardır. Diğer beş boyutun kapsamadığı ancak "mutluluk araştırması" literatüründen bilinen yönlere odaklanır. Hoşgörü̈, hayattan zevk almak ve eğlenmekle ilgili temel ve doğal insan arzularının nispeten özgürce tatmin edilmesine izin veren bir toplum anlamına gelir. Kusıtlama, ihtiyaçların tatminini kontrol eden ve katı sosyal normlar aracılığıyla düzenleyen bir toplum anlamına gelir. Hoşgörü Güney ve Kuzey Amerika'da, Batı Avrupa'da ve Sahra Altı Afrika'nın bazı bölgelerinde hâkim olma eğilimindedir. Doğu Avrupa'da, Asya'da ve Müslüman dünyasında kısıtlama hakimdir. Akdeniz Avrupası bu boyutta orta bir pozisyon almaktadır (Hofstede, 2011). 


\subsection{Hampden - Turner \& Trompenaars: Kapitalizmin Yedi Kültürü}

Trompenaars (1996), kültürü tanımlamak için bir soğanın katmanları metaforunu kullanmıştır. Dış katman insanların temel olarak kültür ile bağdaştırdıkları şeylerdir: dil, yiyecek, giyecek gibi gözlemlenebilir gerçekler. Orta katman bir topluluğun sahip olduğu normlar ve değerleri ifade etmektedir: Doğru ya da yanlış; iyi ya da kötü olarak tanımlanan nedir? En iç katmanı anlamak, diğer kültürler ile başarılı bir şekilde çalışmanın anahtarıdır. Bir toplumun karşı karşıya kaldığı süreklilik gösteren problemler ile baş etmek için geliştirdiği kurallar, metotlar serisini içermektedir. Bu problem çözme oldukça temeldir ve artık bunun nasıl yapıldığın farkında olmaksızın yapılmaktadır. Bu bilinç dışı çözümler, temel varsayımlar olarak tanımlanmaktadır (Trompenaars, 1996: 51).

Charles Hampden-Turner kültürü evrensel problemlerden ortaya çıkan ikilemleri çözmenin yolu olarak ortaya koymuştur. Bu ikilemlerin uzlaştırılması strateji oluşturmanın temelini oluşturmaktadır (Trompenaars, 1996: 52). Kültürel tercihlerin ve değerlerin ulusal kimliğin temel taşları ve ekonomik açıdan güçlü ve zayıf noktaların kaynağı olduğunu ortaya koymuşlardır. Ekonomik faaliyetlerin temelini oluşturan ürün ve hizmetleri yaratırken, hangi sistemlerin gerekli olduğunu kuruluşlar nasıl karar vermektedirler? Yedi temel ikilemin çözümlenerek, tüm değerlerin uyumlu hale getirilmesi servet yaratmanın koşulu olarak ortaya koyulmuştur (Hampden - Turner ve Trompenaars, 1995: 5 - 6).

Her ülke ve her organizasyon (a) insanlarla ilişkilerindeki ikilemler (b) zaman ile ilişkilerindeki ikilemler (c) çevre ile ilişkilerinde ortaya çıkan ikilemler ile karşı karşıya kalmaktadır. Kültürlerin farklılaşması bu ikilemlere nasıl yaklaştıklarına bağlı olarak değişmektedir (Trompenaars, 1996: 52). Trompeenars (1993), kültürü bir grup insanın problemleri çözdüğ̈̈ bir yol olarak tanımlamaktadır. Bu Schein'in (1985), doğrudan örgütsel kültür tanımlamasına dayanmaktadır. Üç tür problem (diğer insanlarla ilişkiler, zaman ve çevre) çözümünden yola çıkarak yedi temel kültür boyutu tanımlamıştır. Trompeenars'ın kültür tanımlaması ulusal ve organizasyonel kültürler arası genel bir tanımlamadır (Chanchani ve Theivanathampillai, 2009: 8). Trompeenars'in boyutları Parsons'in 1951 y1lındaki ve Parsons ve Shils'in yine 1951 yılında yaptı̆̆ 1 sosyolojik çalışmaya dayanmaktadır (Magnusson, Wilson, Zdravkovic, Zhou, Westjohn, 2008: 185). Boyutlardan beşi Parsons'un The Social System'de yer alan boyutları ile benzerdir: evrensellik - ayrıntıcılık, tarafsız ilişkiler - duygusal ilişkiler, ulaşılmış statü - ulaşılmak istenen statü, çözümleme - bütünleme, bireycilik - toplumculuk (Chanchani ve Theivanathampillai, 2009: 8). Parsons'un bu beş boyutuna ilave olarak Trompenaars zaman ve çevre yaklaşımı olarak iki yeni yaklaşım daha eklemiştir (Magnusson, Wilson, Zdravkovic, Zhou, Westjohn, 2008: 185)

Evrensellik - Ayrıntıcılık: Evrensel kültürler insanlığa genel güvensizliği yansıtmakta ve kurala dayalı davranışları desteklemektedir. Diğer yandan ayrıntıcılığa önem veren kültürler mevcut koşulların istisnai durumlarına daha fazla önem vermektedirler. Zurcher ve grubu (1965), bu sınıflandırmayı desteklemektedir. $\mathrm{Bu}$ boyut, iş seyahatlerinin zamanlaması, kontratlar, iş değerlendirme ve ödüllendirme ve merkez ofisin rolü gibi uluslararası işletmenin pek çok yönünde uygulama alanı bulmuştur (Akt: Chanchani ve Theivanathampillai, 2009, 8; Trompenaars, 1993: 46). Yüksek düzeyde evrenselliğin egemen olduğu toplumlarda, resmi kurallar ve sözleşmelere ve bireysel koşullar göz önünde bulundurulmaksızın bu kural ve sözleşmelerin uygulanmasına vurgu yapılmaktadır. Yüksek düzeyde ayrıntıcılığa önem veren kültürlerde ise ilişkiler ve güvene vurgu yapılmaktadır. Kurallar yalnızca bir arkadaşa yardım etmek adına kullanılabilir (Gooderham, Nordhaug, 2003: 141).

Bireycilik - Toplumculuk: Trompenaars tanımladığı bu boyut bireyler ve toplumlar arasındaki çatışmayı temsil etmektedir. Parsons ve Shils gibi, Trompenaars (1993) da bireyciliği kişinin kendine yönelimi ve toplumculuğu ise ortak amaçlar ve hedeflere yönelim olarak tanımlamıştır. Uluslararası işletmede müzakereler, karar verme ve motivasyon, bireysel ya da 
toplumcu tercihlerden etkilenmektedir (Akt: Chanchani ve Theivanathampillai, 2009: 9; Trompenaars, 1993: 47). Toplulukçu kültürlerde bireyler kendilerini bir gruba ait olarak görürlerken, bireyci toplumlarda kişiler kendilerini bağımsız bireyler olarak görmektedirler (Gooderham, Nordhaug, 2003: 141).

Tarafsız İlişkiler - Duygusal İlişkiler: Bu boyut, ifade edilen duyguların sınıflandırılmasını içermektedir. Mantık ve duygu insanlar arasındaki ilişkilerde önemli rol oynamaktadır. Bu duyguların hangisinin ağır basacağı bireylerin duygusal (duygularını gösteren) ya da tarafsız (duygularını göstermeyen) olduklarına bağlıdır. Trompenaars, Parson ve Shils'in bu boyutunu anlamak için iletişimi (sözlü-yazılı) ve mizacı eklemiştir. Bu boyut ulusal kültürel bağlamda uygulanabilir değildir. Mizaç, sübjektiftir ve bireye bağlıdır. Keyfi uygulamalar söz konusu olabilir (Chanchani ve Theivanathampillai, 2009: 9). Tarafsız ilişkilerin ön planda olduğu kültürlerde kişiler arası iletişimde duygular açıkça ifade edilmemektedir. Diğer taraftan, duygusal ilişkilerin yoğun olduğu kültürlerde iş ile ilgili kararlarda bile duyguların açıkça ifade edilmesi söz konusu olmayabilir (Gooderham, Nordhaug, 2003: 141).

Çözümleme - Bütünleme: Çözümlemeci ve bütünlemeci kültürler, farklı iletişim alanlarında bireylerin yer alma yollarını araştırmaktadır (yüksek düzeyde paylaşılan bilgi gerekmektedir). Çözümlemeci toplumlarda, iş gereklilikleri diğer meşguliyetlerden ayrılmaktadır. Çözümlemeci bir kültürde, yönetici ve çalışanın, iş yapış şekilleri konusunda kapalı bir iletişim temeli bulunmaktadır ve bu durum esneklik ve uyumluluğu gösteren sosyal yapılardan farklıdır. Bütünlemeci toplumlarda, CEO yalnızca şirketi yönetmez aynı zamanda bireylerin değerleri, organizasyonun işleyişi ve sosyal yapılar boyunca paylaşılmaktadır. $\mathrm{Bu}$ boyut uluslararası yapılarda değerlendirme konularında ayrı bir öneme sahiptir, ulusal bağlam ile ilgili görünmemektedir (Chanchani ve Theivanathampillai, 2009: 9). Çözümlemeci kültürlerde özel yaşam ve iş yaşamı arasında ayrım yapılmaktadır. Bireyler iş ve özel yaşamlarını birbirinden ayırabilmektedirler. Bütünlemeci toplumlarda ise iş ve özel yaşam birbiriyle yakın bir şekilde bağlantılıdır ve geniş çeşitlilikteki sosyal statüler arasında önemli ölçüde resmiyet sürdürülmektedir (Gooderham, Nordhaug, 2003: 141).

Ulaşılmış Statü - Ulaşılmak İstenen Statü: Bazı toplumların bireylerine ve onların faaliyetlerine dayanılarak diğerlerinden daha fazla statü verilmektedir. Bazı toplumlar, kişilere başarılarına bağlı olarak, diğerleri ise yaş, sınıf, cinsiyet ve diğer faktörlere bağlı olarak statü vermektedirler. Birincisi kazanılmış statü, ikincisi ise verilmiş statüdür. Her ne kadar Trompenaars tarafından ortaya koyulmasa da Parsons'a (1977), göre toplumların gelişimi ayrıntıcılık yerine evrenselliğin, ulaşılmış statü ile ulaşılmak istenen statünün yer değiştirmesi ile gerçekleşmektedir (Chanchani ve Theivanathampillai, 2009: 9). Başarı odaklı kültürlerde bireylere statü, eğitim ve deneyim düzeyleri, görevlerini ne kadar iyi gerçekleştirdiklerine bağlı olarak verilmektedir. Statü odaklı kültürlerde ise yaş, akrabalık, cinsiyet vb. özelliklere göre statü verilmekte ve statü farklılıkları daha fazla ön plana çıkmaktadır. Bu tarz kültürlerde güç, başarı odaklı kültürlerde olduğu gibi meşrulaştırma gerektirmez (Gooderham, Nordhaug, 2003: 141).

Zaman Yaklaşımı: Zaman algısı, ardışı ve eş zamanlı olarak değişiklik gösterebilmektedir. Kluckhohn ve Strodtbeck (1961), geçmiş, şimdiki ve gelecek zaman yöneliminin kültürün merkezi boyutu olduğunu ortaya koymuşlardır ve bu durum bireylerin faaliyetlerini koordine etmelerine olanak vermektedir (Akt: Chanchani ve Theivanathampillai, 2009: 9). Bu yapı hem bireyler hem de gruplar için önemli etkiler içermektedir. Geçmiş / şimdiki zaman odaklı toplumlar geçmişte gerçekleşen olaylara ve zaferlere önem vermektedirler. Fransa, İspanya, Portekiz, Arap ülkeleri bunlara örnek olarak verilebilir. Gelecek odaklı toplumlar ise planlama ve gelecekte mümkün olabilecek durumlara odaklanmaktadırlar. Çin, Japonya, Kore, İsveç, ABD bu ülkelere örnek olarak gösterilebilir (Nardon ve Steers, 2009: 6). 
Çevre Yaklaşımı: Trompenaars çevre boyutunu, önemli bir kültürel değişken olarak belirlemektedir. Toplumlar çevre konusunda iki temel eğilime sahiptirler: bireyler, kendi isteklerini çevreleri üzerinde empoze ederek doğayı kontrol edebilirler (içe yönelik yönlendirme). Diğer taraftan insanın doğanın bir parçası olduğunu ve kurallara, yönlendirmeye ve güçlerine uyum sağalması gerektiğini ifade etmektedir (dışa yönelik yönlendirme). Bu görüş, Rotters'ın (1969), kontrol odağı anlayışına dayanmaktadır ve bazı açılardan Hofstede'in belirsizlikten kaçınma kültürel boyutu ile örtüşmektedir (Chanchani ve Theivanathampillai, 2009: 10).

\subsection{Schwartz'ın Değer Kuramı}

Schwartz ve arkadaşları daha psikolojik bir bakış açısı ile sosyal değerler arasındaki temel farkın ifade ettikleri motivasyonel amaçlar olduğunu öne sürmüşlerdir. İhtiyaçları, sosyal güdüleri, sosyal kurumsal talepleri yansıtsan on evrensel insani değer tanımlamışlardır. Bu değerler bütün kültürlerde bulunmakta ve insan varlı̆̆ının evrensel ihtiyaçlarını temsil etmektedir: güç, başarı, hazcılık, uyarılım, özyönelim, evrensellik, iyilikseverlik, geleneksellik, uyma, güvenlik (Akt: Nardon ve Steers, 2009: 5; Kağıtçıbaşı, 1997).

Schwartz (1994), bireysel ve kültürel analiz düzeylerinin bağımsız olduğunu savunmaktadır. Birey düzeyindeki boyutlar, günlük yaşamda değerlerine göre hareket ederken deneyimledikleri psikolojik boyutları; kültür düzeyi boyutları ise bireylerin faaliyetlerini düzenlemek için toplumların bulduğu çözümleri yansıtmaktadır. Kültürel düzey analizinde, Schwartz üç boyut tanımlamıştır: muhafazakarlık - otonomi, hiyerarşi - eşitlikçilik, egemenlik uyum. Schwartz'ın modeli, sosyal davranışın temel alanlarına uygulanmış ancak örgütsel çalışmalardaki uygulaması sınırlı kalmıştır (Akt: Nardon ve Steers, 2009: 6; Bond, 2001).

Schwartz (1992), çalışmasında farklı kültürlerin 10 farklı özellik üzerinden tanımlanabileceğini belirtmektedir. Ortaya koyduğu bu on değer ile bireysel ve toplumsal kültür değerlendirmesi yapılabileceğini savunmuştur. (Akt: Sığrı, Tabak, Ercan, 2009: 170 - 171; Schwartz, 1992). Değerlerin hangilerinin birbiriyle uyum içerisinde olduğunu, hangilerinin birbirinin karşıtı durumunda olduğunun tespit edilmesidir. Schwartz (2012) tarafından yeniden tartışılan değerler ve bu değerlerin anlamları aşağıda açıklanmıştır:

Güç (Power): Sosyal statü ve prestij, insanlar ve kaynaklar üzerinde kontrol veya hakimiyet durumu. Sosyal kurumların işleyişi, görünüşe göre, bir dereceye kadar statü farklılaşmasını gerektirir. Hem kültürler içinde hem de kültürler arasında kişilerarası ilişkilerin çoğu ampirik analizinde bir baskınlık/teslimiyet boyutu ortaya çıkarmaktadır. Sosyal hayatın bu gerçeğini haklı çıkarmak ve grup üyelerini bunu kabul etmeye motive etmek için gruplar, güce bir değer olarak bakmalıdır. Otorite, zenginlik, sosyal güç, kamusal imajımı korumak, sosyal tanınma ve benzeri değerler buna örnektir. Hem güç hem de başarı değerleri sosyal itibara odaklanır. Bununla birlikte, başarı değerleri (örneğin, hırslı olma), somut etkileşimde başarılı performansın aktif bir şekilde gösterilmesini vurgularken, güç değerleri (örneğin, otorite, zenginlik) daha genel sosyal sistem içinde baskın bir konumun elde edilmesini veya korunmasını vurgular.

Başarı (Achievement): Sosyal standartlara göre yeterlilik göstererek kişisel başarı. Bireylerin hayatta kalabilmesi, grupların ve kurumların amaçlarına ulaşabilmesi için kaynak üreten yetkin performans gereklidir. Burada tanımlandığı gibi, başarı değerleri, hâkim kültürel standartlar açısından yeterlilik göstermeyi ve böylece sosyal onay almayı vurgular (hırsl1, başarıl1, yetenekli, nüfuzlu).

Zevk (Hedonism): Kişinin kendisi için zevk veya duyusal tatmin duyması. Hedonizm değerleri, organizmanın ihtiyaçlarından ve onları tatmin etmenin verdiği hazdan türer (Zevk, hayattan zevk alma, rahatına düşkün olma). 
Uyarım (Stimulation): Heyecan, yenilik ve yaşamda meydan okuma. Uyarım değerleri, tehdit edici olmaktan çok olumlu bir aktivasyon düzeyini sürdürmek için organizmanın çeşitlilik ve uyarım ihtiyacından türer. Bu ihtiyaç muhtemelen öz-yönelim değerlerinin altında yatan ihtiyaçlarla ilgilidir (değişken bir yaşam, heyecan verici bir yaşam, cüretkâr olma).

Öz Yönelim (Self direction): Bağımsız düşünce ve eylem - seçme, yaratma, keşfetme. Öz-yönetim, kontrol ve ustalık için organizmanın ihtiyaçlarından ve özerklik ve bağımsızlığın etkileşimsel gereksinimlerinden kaynaklanır (yaratıcılık, özgürlük, kendi amaçlarını seçme, meraklı, bağımsız, özsaygı, mahremiyet).

Evrensellik (Universalism): Tüm insanların ve doğanın refahı için anlayış, takdir, hoşgörü ve koruma duygusudur. $\mathrm{Bu}$, iyilikseverlik değerlerinin grup içi odağıyla çelişir. Evrensellik değerleri, bireylerin ve grupların hayatta kalma ihtiyaçlarından kaynaklanır. Ancak insanlar, genişletilmiş birincil grubun ötesindeki diğerleriyle karşılaşana kadar ve doğal kaynakların kıtlığının farkına varıncaya kadar bu ihtiyaçların farkına varmazlar. İnsanlar daha sonra, farklı olan diğerlerini kabul etmemenin ve onlara adil davranmamanın, yaşamı tehdit eden çekişmelere yol açacağını anlayabilir. Ayrıca, doğal çevreyi korumadaki başarısızlığın, yaşamın bağlı olduğu kaynakların yok olmasına yol açacağını da fark edebilirler (geniş fikirli olma, sosyal adalet, eşitlik, barış içinde dünya, doğa ile birlik, bilgelik, çevreyi koruma).

Yardımseverlik (Benevolence): S1k sık kişisel temasta bulunanların ("grup içi") refahını korumak ve arttırmak olarak tanımlanabilir. Yardımseverlik değerleri, grup işleyişi için temel gereksinimden ve bireye ait aidiyet ihtiyacından türer. En kritik olanı, aile ve diğer birincil gruplar içindeki ilişkilerdir. Yardımseverlik değerleri, başkalarının refahı için gönüllü ilgiyi vurgular (yardımsever, dürüst, bağışlayıcı, sorumlu, sadık, gerçek dostluk, olgun, sevgi dolu).

Geleneksellik (Tradition): Kişinin kültürünün veya dininin sağladığı gelenek ve fikirlere sayg1, bağl1lık ve kabul etme durumudur. Her yerde gruplar, ortak deneyimlerini ve kaderlerini temsil eden uygulamalar, semboller, fikirler ve inançlar geliştirir. Bunlar, değerli grup gelenek ve görenekleri olarak onaylanır hale gelir. Grubun dayanışmasını sembolize eder, eşsiz değerini ifade eder ve hayatta kalmasına katkıda bulunur. Genellikle dini ayinler, inançlar ve davranış normları şeklini alırlar (geleneğe saygı, alçakgönüllü, dindar, hayattaki payımı kabul eden). Gelenek ve uygunluk değerleri özellikle motivasyon açısından birbirine yakındır; benliği toplumsal olarak dayatılan beklentilere tabi kılma amacını paylaşırlar. Gelenek, dini ve kültürel gelenekler ve fikirler gibi daha soyut nesnelere tabi olmayı gerektirir.

Kurallara Uyma (Conformity): Başkalarını üzmesi veya onlara zarar vermesi ve sosyal beklentileri veya normları ihlal etmesi muhtemel eylemlerin, eğilimlerin ve dürtülerin kısıtlanmasıdır. $\mathrm{Bu}$ değer, bireylerin sorunsuz etkileşimi ve grup işleyişini bozabilecek ve baltalayabilecek eğilimleri engelleme gereksiniminden kaynaklanmaktadır. Onları tanımladığım gibi, genellikle günlük etkileşimde kendini kısıtlamayı vurgular (itaatkâr olma, öz disiplin, kibarlık, ana-babaya ve yaşl1lara saygıl1).

Güvenlik (Security): Toplumun, ilişkilerin ve benliğin güvenliği, uyumu ve istikrarı. Güvenlik değerleri, temel bireysel ve grup gereksinimlerinden türer. Bazı güvenlik değerleri öncelikle bireysel çıkarlara, diğerleri daha geniş grup çıkarlarına (örneğin ulusal güvenlik) hizmet eder. Bununla birlikte, ikincisi bile, önemli ölçüde, kişinin kendisi veya özdeşleştiği kişiler için güvenlik hedefini ifade eder (sosyal düzen, aile güvenliği, milli güvenlik, iyiliklerin karşıllı̆̆1).

Söz konusu on kültürel değer dünya genelindeki kültürlerde bulunma dereceleri ve hiyerarşik sıralamalarına göre değerlendirilmiştir (Akt: Sığrı, Tabak, Ercan, 2009: 173). Bu değerlerin sıralaması bireylerin ve genel olarak toplumların olaylara yaklaşımı hakkında fikir vermektedir. Schwartz'ın önderliğinde, 55 farklı ülkeden 155 farklı örnekleme uygulanan anketler yukarıda belirtilen yaklaşımı yeterli derecede desteklemiştir (Akt: Sığrı, Tabak, Ercan, 
2009: 173; Schwartz 1994; Schwartz ve Sagiv 1995). On değerin hem tek başına hem karş1 yönde veya birbirini destekler yönde farklı ülkelerde kendi mantı̆̆ına uygun bir şekilde ortaya çıktığı bulgulanmıştır. Örneğin, başarı (achievement) genellikle yardımseverlik (benevolence) değeri ile çatışmaktadır. Birisi kişinin kendi başarısına odaklanma anlamını ihtiva etmekte iken diğeri başkalarının başarısını artırmak için yardım etme anlamına gelmektedir. Aynı şekilde geleneksellik (traditional) değeri ile uyarım (heyecan- stimulation) değeri çatışır. Öte yandan yardımseverlik ile kurallara uyarlılık (conformity) değerlerinin her ikisi de grubun onayını kazanan hareketler olduğu için benzer değerler olarak nitelendirilirler. Ayrıca, güç (power) ve güvenlik (security) değerlerinin de her ikisi de belirsizlikten kaçınma ve ilişkileri ve kaynakları kontrol etme anlamında oldukları için benzerlikler gösterirler (Sığr1, Tabak, Ercan, 2009: 173 174).

Kültür düzeyi analizinde, Schwartz üç farklı boyut tanımlamıştır:

Muhafazakarlık - Otonomi: Bireylerin ne ölçüde grup içerisinde bir araya geldiğinin göstergesidir. Muhafazakarlık, bireylerin topluluk içerisine yerleşmiş, yaşamanın yolunu paylaştıkları grup ile katılım ve kimlik tanımlaması vasıtası ile anlam bulmaktadırlar. Mevcut durumun ne ölçüde korunduğu ile ilgilidir (Nardon ve Steers, 2009: 7). Geleneklerin, güvenliğin, uyumun öncelikler olarak benimsendiği, birbirine bağlı sosyal ilişkilere dayanan toplumların özellikleridir. $\mathrm{Bu}$ değerler mevcut durumu ve kuralları, geleneksel olarak oluşturulmuş düzeni (sosyal düzen, geleneklere saygı, boyun eğme, aile güvenliği, öz disiplin) değiştirmeyi amaçlayan bireysel hareketlerden kaçınmayı vurgulamaktadır (Gouveia ve Ros: 2000, 26).

Otonomi, bireylerin gruplardan bağımsız olduğunu ve anlamı kendi tek varlıklarında bulmalarını ifade etmektedir. İki tür otonomi bulunmaktadır: Entelektüel otonomi, fikirler ve haklarının peşinde bağımsızlık, bağımsız entelektüel fikirler, yaratıcılık, merak konusunda ne kadar vurgu yapıldığını ifade etmektedir (Nardon ve Steers, 2009: 7). Bireyi, kendi amaçları ve entelektüel ihtiyaçları (merak, yaratıcılık, açık fikirlilik) izleyen bağımsız varlıklar olarak konumlandıran değerleri içermektedir (Gouveia ve Ros, 2000: 26). Etkisel otonomi ise etkili bir şekilde olumlu deneyimler peşinde bağımsızlık, etkili hazcılık ve uyarılma konusunda ne kadar vurgu yapıldığı ile ilgilidir (Nardon ve Steers, 2009: 7). Olumlu etkili deneyimlerin (zevkli ve heyecanlı bir hayat) elde edilmesini destekleyen ihtiyaçlardır. Bu değerler, entelektüel otonomi ile kişisel ihtiyaç ve müzakere edilmiş anlaşmalar doğrultusunda diğerleri ile bağlantıyı vurgulayan bağımsız birey kavramını paylaşmaktadır. Her iki otonomi de toplumculuk karşıııdır (Akt: Gouveia ve Ros, 2000: 26; Schwartz, 194).

Hiyerarşi - Eşitlikçilik: Eşitlik ne ölçüde değerlidir ve beklenmektedir? Hiyerarşik kültürlerde bireyler, rollerine uygun davranmak üzere sosyalleşmektedirler; eğer gerçekleştirmezler ise cezalandırılırlar. Toplumda gücün eşitsiz dağılımının kabul edilmesini ifade etmektedir (Nardon ve Steers, 2009: 7). Sabit kaynakların ve hiyerarşik olarak kazanılmış rollerin (sosyal güç, otorite, zenginlik, boyun eğme) meşruluğuna vurgu yapmaktadır. Muhafazakarlık değeri ile birlikte, kültür ve toplumları tanımlamak için geniş bir şekilde kullanılan toplumculuk boyutunun temelini oluşturmaktadır (Akt: Gouveia ve Ros, 2000: 26; Hofstede, 1984; Triandis, 1990). Eşitlikçilik değerinde ise, bireyler, insan olarak temel ihtiyaçları paylaşan ahlaki eşitler olarak görülmektedir. Grup çıkarı doğrultusunda kişisel ihtiyaçlardan vazgeçebilme isteğini ifade etmektedir (Nardon ve Steers, 2009: 7). Diğerlerinin refahını (eşitlik, sosyal adalet, sorumluluk, yardım), göz önünde bulunduran toplumlardır. Bu değerler toplulukçu kültürlerde çok önemli değildir. Bu durum, entelektüel ve etkisel otonomi ile pozitif yönde, toplumculuk ile ise negatif yönde bağlantılıdır (Gouveia ve Ros, 2000: 27).

Egemenlik - Uyum: Kişisel ya da grup ihtiyaçları için insanların ne ölçüde doğal ve sosyal dünyayı değiştirmek istedikleridir Egemenlik, bireylerin, kendi savlarını öne sürerek ileri gitmesi, kişisel ve grup ihtiyaçlarını geliştirmek için sosyal ve doğal dünyayı geliştirmeyi 
amaçlamaları anlamına gelmektedir. Bir toplumun kendi çevresini kontrol etme isteğidir. Uyumda ise, bireyler dünyayı olduğu gibi kabul etmekte ve onu ele geçirmekten çok korumaya çalışmaktadırlar. Doğa ile uyum içerisinde olma çabasıdır (Nardon ve Steers, 2009, 7). Bireyselcilik - toplulukçuluk boyutuna benzemektedir. İki kutuplu boyutu oluşturan prensip, bireye faydalı olacak değerleri savunmak ile toplumun faydasına olacak değerleri koruma arasındaki karşıtlığ ifade etmektedir (Akt: Gouveia ve Ros, 2000: 27; Hofstede, 1984; Kagitçibasi ve Berry, 1989; Schwartz \& Ros, 1996; Triandis, 1990, 1994).

Hiyerarşi ve egemenlik, uyum ve eşitlikçi yaklaşım değerleri ile karşılaştırıldığında ilk değerler diğerleri pahasına kişi ya da grupların ihtiyaçlarının karşılanmasını meşrulaştırmaktadır, diğerleri ise sosyal ve materyal çevreyi korumak için kişi ihtiyaçlarından vazgeçmeyi gerektirmektedir. Hiyerarşi ve eşitlikçi yaklaşım, bireylere eşit olarak davranılması gerekip gerekmediği konusunda karşıtlık içermektedir. Egemenlik ve uyum ise, sosyal çevreye uyum ve değişim konusunda karşıttırlar (Gouveia ve Ros, 2000: 27).

\subsection{Kültür Modellerinin Değerlendirilmesi ve Karşılaștırması}

Hofstede'in kültür modeli incelendiğinde ele aldığı kavramlar basit kavramlar olarak değerlendirilmiş ve yapılan sınıflandırmanın iki nedenden dolayı derinlikli ve özel olmadığı ifade edilmiştir. Birincisi, belirsizlikten kaçınma değeri, etraflı olmadığı ve doğuya özgü değerleri içermediği için eleştiriler ile karşılaşmıştır. İkincisi ise uzun vadeli yönelimin modele geç dahil edilmesinin modelin kendine özgü özellik içermediğini göstermesidir.

Analiz düzeyi açısından bakıldığında ise, Hofstede, sınıflandırmasının yalnızca ulus düzeyinde uygulanabileceğini savunmuştur. Hofstede, boyutlarının başka bir düzeye uygulanmasının yanlış olacağını belirtmiştir. $\mathrm{Bu}$ nedenle Hofstede'in modeli farklı analiz düzeylerine uygulanma açısından zayıf bir model olarak değerlendirilmektedir.

Farklı araştırma metotlarına uygulama açısından değerlendirildiğinde ise, Hofstede tarafindan belirlenen (VSM kullanarak ülkeler arasında ortalama farklılıklarının kıyaslanması) metot dişında herhangi bir metodun uygulanması hatalı olarak değerlendirilmektedir. Hofstede'in verisi geniş bir kullanım alanına sahip olsa da bu boyutların diğer araştırma metotlarına (deneysel, yarı deneysel, alan araştırması vb.) uygulanması mümkün görünmemektedir. Hofstede'in kültür modeli, bir ya da daha fazla boyutta kültürler arasında ve kültürün kendi içerisinde baskın temaları belirlemek için kullanılabilir. Temaların belirlenmesi içsel olarak tutarlıdır ancak Hofstede'in sınıflandırması, bu boyutların hangilerinin belirli bir kültür için daha derin bakış açısı sağlayabildiklerini ortaya koymamaktadır. Kültürel değişiklik anlayışı açısından, Hofstede'in çerçevesi açık bir şekilde kültürel değişimin sistematik bir çalışmasına olanak tanımamaktadır. Ancak araç ve metodun tanımlanmış uygulaması zamanın belirli noktalarında kültüre dair enstantaneleri sağlayabilir. Bu enstantaneler değişim sürecinin göstergesi olmamakla birlikte değişimin yönü ve büyüklüğünün göstergesi olabilirler.

Trompenaars tarafindan ortaya koyulan boyutlara bakıldığında ise basit değil, oldukça karmaşık yapılar olduğu görülmektedir. Örneğin, çevreye yaklaşım boyutu basit görünmekte ancak verilen statü gibi belli başlı konular uygulaması ve algılaması oldukça karmaşık konulardır. Boyutlar, geniş bir şekilde ele alınmakla birlikte kendine has özellikler taşımamaktadır. Çevreye yaklaşım ve bireyselcilik boyutları oldukça benzerdir. Çevreye yaklaşım, "içe dönük" olanların kontrolünün kendi içlerinde olduğu noktasından ortaya çıkmıştır; bireyselcilik kavramı da buna çok benzerdir (Chanchani ve Theivanathampillai, 2009: 10). Trompenaars tarafindan toplanan veriler; temelde 2 boyuttan oluşan bir kültürel değerler teorisi ortaya koymaktadır. Trompenaars'ın eşitlikçi taahhüdü, kişisel, belirli ilişkiler ve verilen statü yerine, evrensel ilişkilerin, başarıya bağli statünün tercih edilmesini ifade etmektedir. İkinci boyut faydacı bağl1lık ise aileye bağlllık ve toplumcu sorumlulukların tercih edilmesini ifade etmektedir (Basabe, Ros, 2005: 192 - 193). 
Trompenaars'ın boyutlarının analizinin farklı düzeylere uygulanması açısından değerlendirildiğinde, farklı analiz düzeylerine kolaylıkla uygulanabileceği düşünülmektedir. Bu psikolojik karakterlerin, örneğin birey düzeyinden ulus düzeyine geçişi test edilmemiş bir alandır ve gelecek araştırmalar için önemli bir noktadır. Bu nedenle sınıflandırma analiz düzeyleri geçişinde ortalama düzeydedir. Farklı araştırma metotlarının uygunluğu açısından değerlendirildiğinde, yapılar kesinlik ve doğruluk açısından oldukça yetersizdir ve bu nedenle değerlendirmeyi sınırlandırmaktadır. Boyutlar ve uygulama, ampirik kanıtlara dayanan, titizlikle çalışılmış, çaba gerektiren bir uzmanlıkla teoriye odaklanmaktan çok anekdota dayalı bir çalışma olarak değerlendirilmektedir. Farklı araştırma metotlarına uygulanması bu nedenle sübjektif, kesin olmayan ve sorgulanabilir bir değer yaratacaktır. Bu nedenle boyutlar, farklı araştırma metotlarının çabasına girdi sağlama açısından yetersiz kalmaktadır. Boyutlar aynı zamanda baskın temaları belirlemek konusunda yetersiz kalmaktadır, çünkü boyutlar, bireyin psikolojisi açısından yakından incelenmiş ve belirginleşmiştir; bu nedenle baskın temaları belirlemek ve açığa çıkarmak oldukça zor olacaktır. Kültürel değişiklikleri açıklamada kavramlar boyutlar için ve boyutlar arasında değerlendirmeden yoksundurlar. "Çevre ve zamana karşı yaklaşım" gibi bazı boyutlarda değişimi açıklama söz konusu değildir (Chanchani ve Theivanathampillai, 2009: $10)$.

Hofstede'in ve Trompenaars'ın araştırmalarını kıyaslamak bir açıdan problematiktir. Çünkü genellikle oldukça farklı kültürel boyutları araştırmaktadırlar. Ancak araştırmaları bir boyut açısından benzerdir: Trompenaars'ın toplulukçuluk - bireyselcilik boyutu, Hofstede' in bireyselcilik - toplulukçuluk boyutu ile benzerdir. Ülkelerin sınıflandırılmasında her iki araştırma sonucunda elde edilen sonuçlar geniş ölçüde tutarlılık göstermektedir. Örneğin, Japonya ve Hindistan, Hofstede ve Trompenaars'a göre, bireyselcilik anlamında zayıftırlar; Danimarka, İngiltere ve ABD ise bireyselci toplumlar olarak görülmektedir. Ancak, pek çok ülke Trompenaars'ın araştırmasına göre Hofstede'in araştırmasından daha bireyselcidir. Bu durum, Meksika, Yunanistan ve İspanya için söz konusu olmuştur. Bu tarz farklılıklar tamamen, Hofstede ve Trompenaars tarafından kullanılan ölçeklerin farklı olması ile açıklanamamaktadır. Hodgetts ve Luthans (2000), bu farklılıkların, her iki araştırmadaki zaman diliminin farklı olmasından kaynaklanabileceğini ve bu durumun da kültürlerdeki değişimi gösterebileceğini ortaya koymuşlardır. Trompenaars ayrıca araştırmasını ulus kavramı aracılı̆̆ kültürlerini araştırarak genişletmiştir. Bunu yapmak için başka bir boyut kullanmıştır: Eşitlik Hiyerarşi. Hiyerarşik şirket kültürü liderin önemli ölçüde otoriteye sahip olduğu ve en iyiyi bildiği güç odaklı kültürlere sahiptirler. Bu boyut Hofstede'in güç mesafesi kavramına benzemektedir. Ayrıca aralarında önemli ölçüde benzerlik bulunmaktadır. Trompenaars'a göre İskandinav ülkeleri, Kuzey Amerika ve İngiltere nispeten eşitlikçi ülkelerdir ve Hofstede'in araştırmasında göre düşük güç mesafesine sahiptirler (Gooderham, Nordhaug, 2003: 145).

Hofstede ile kıyaslandığında, Trompenaars'ın çizdiği çerçeve daha çağdaştır; teorik olarak güçlü, daha karmaşık ve sistematik teknikler kullanılmıştır. Hofstede'in verilerinin toplandığ 1 1960'lı yıllardan itibaren kültürel değerlerdeki değişmeleri yakalamış daha güncel verilerdir. Hofstede'in orijinal çalışmasından farklı olarak son dönemde yapılan çalışmalar ilave araştırmalar, birleştirilmiş ilave teorik görüşler ve metodolojik ilerlemelere dayanmaktadır. Hofstede'in araştırmasının yapıldığ 1 1960'ların sonundan itibaren kültürel değerlerde gerçekleşen değişiklikleri içerebilir (Magnusson, vd., 2008: 185). Hofstede ve Trompenaars'in örgütsel düzeydeki çıkarımlarına rağmen bu düzeyde ulusal kültür tipolojilerini kullanmaları nedeni ile beklentilerin gerisinde kaldıkları ifade edilmektedir. Bu nedenle Trompenaars zaman açısından geleceğe dair yönelimin şirket stratejisinin temel taşlarından birisi olduğunu ortaya koymaktadır ancak uzun vadeli yönelimlere sahip bütün ülkeler aslında yüksek kişi başı gelire sahip olmayabilir (Jacob, 2005: 518).

Hofstede'in kültürler arası sınıflandırma yapmak için kullandığ beşinci boyutu olan uzun vadeli yönelimlere karşı kısa vadeli yönelimler boyutu, tutarsızlıklar içermektedir. 
Hofstede hem uzun vadeli yönelimlere hem de kısa vadeli yönelimlere Konfüçyüs değerleri yerleştirmiştir. Kısa vadeli yönelimin bileşenlerinin bu fenomeni nasıl karakterize ettiği net değildir. Bu bileşenlerin bazıları farklı bir mantık kullanarak etkili bir şekilde uzun vadeli yönelimleri yansıtabilmektedir. "Statüye göre ilişkilerin düzenlenmesi" neden uzun vadeli yönelimin bir bileşeni iken "geleneğe saygı" kısa vadeli yönelimin bir bileşenidir? Örneğin, "geleneğe saygı", bütün hepsinin uzun vadede zenginliğe katkı sağlayacağı, süreklilik, değişmezlik, karmaşadan uzak durmayı içerebilir. Keough ve arkadaşları (1999), Hofstede'in görüşü ile uyum göstermeyen şimdiki zaman, gelecek zaman ve geçmiş zaman yönelimlerini nelerin oluşturduğuna dair geniş kapsamlı yorumlamalarını ortaya koymuşlardır: "Genellikle, geçmiş zaman yönelimli bireyler ve toplumlar, planların toplumun gelenek ve göreneklerine uyumlulukları açısından değerlendirmeleri gerektiğine inanmaktadırlar”. Keough ve arkadaşları, aynı zamanda yüksek geçmiş zaman yönelimine sahip kültürlerin gelecekte fayda sağlamak adına şimdiki davranışı düzeltme eğiliminde olduklarını gözlemlemişlerdir. Bu durum, kültürleri kısa vadeli yönelimler olarak tanımlayan durağan bakış açısına karşıt olarak Hofstede ve Bond'un (1988) "dinamik ve gelecek yönelimli mantalite" olarak tanımladığı uzun vadeli yönelime olanak sağlayan Konfüçyüs Dinamizmi görüşünden oldukça uzaktır (Jacob, 2005: 517).

Zaman yönelimi açısından bakıldığında Hosftede ve Trompenaars'ın, tarafından uzun vadeli zaman yönelimleri açısından birbirine benzer yaklaşımlar ortaya koymasalar da birbirleri ile çelişen sonuçlar ortaya koymaları ile (örneğin Pakistan'ın Trompenaars tarafindan yapılan araştırmada en fazla uzun vadeli yönelime sahip ülkelerden birisi çıkarken Hofstede'de en düşük sonucu alması) ulusal kültürlerin, safhalar halinde siralanan boyutlar ile değerlendirilemeyecek kadar karmaşık yapılar olduğu sonucuna ulaşılmaktadır.

Trompenaars kültürleri ilişki bazlı ya da belirlenen kurallar bazında liderlik tarzlarına sahip olup olmadıkları açısından sınıflandırmaktadır. Liderlik tarzları konusundaki bu sinıflandırma 1950'lili yılların Amerika'sında Fred Fiedler tarafindan ortaya koyulan bir sınıflandırmadır. $\mathrm{Bu}$ yaklaşım, liderlik gibi karmaşık bir konuyu yalnızca iki değişkene indirgemektedir. Ayrıca kültür gibi karmaşık bir olgu, liderlik tarzlarının nasıl olduğu yaklaşımı ile açıklanmaktadır. Fiedler tarafından yapılan çalışmanın amacı her iki liderlik tarzının Amerika'da var olduğunu ortaya koymaktır ancak kendisinden sonra gelen araştırmacılar bu iki liderlik tarzının her yerde var olduğu düşüncesinden hareketle ülkeleri ilişki ya da kural odaklı olarak sınıflandırmalarının amaçsız bir genelleştirmeden ibaret olduğu düşünülmektedir. Hofstede ve Trompenaars'ın tarafından ortaya koyulan uzun mesafeleri içeren araştırmaların, ilke etapta kültürün gözlemlenmesi ve çalışılması ve sonrasında uygun yönetim yaklaşımlarını önermesi amacına hizmet etmediği ve evrensel bir tipoloji oluşturma amacına yönelik metodolojik yaklaşımdan uzaklaştığı ve batı tarzı yönetim modellerinin amaçsız bir şekilde diğer ülkelere transferi üzerine odaklandığ ifade edilmektedir (Jacob, 2005: 519).

Trompenaars ve Hofstede tarafindan ortaya koyulan kültür modellerinde, kültürleri farklılaştırmanın genelleştirmeye doğru bir eğilim oluşturduğu, ulusal kültürler konusundaki bu genelleştirmenin kalıplaşmış yargılar oluşturmayı teşvik ettiği ortaya koyulmaktadır (Hoft, 1999: 145 - 146). Schwartz'ın (1992) çalışması Hofstede'in (1980) çalışmasından daha sonra ortaya konulmuştur. Schwartz'ın çalışmasını özgün kılan husus, bireysel değerlerin davranış, yaklaşım ve toplumsal değerler üzerine etkisinin sosyo-psikolojik bakış açısıyla incelenmesidir. Bu bakış açısı diğer değerlendirmelere göre daha karmaşık bir yapıya sahiptir (Sı̆̆rı, vd., 2009: 170). Schwartz (1994) ve Trompenaars (1994), her bir kültürün; örneğin bir ülkenin, kendi bireylerinin davranışlarını yönlendiren paylaşılan değerler ve normlara sahip olduğunu göz önünde bulundurarak Hofstede ile benzer bir kültür kavramı görüşüne sahiptirler. Ancak, ulusal farklılıkları yarattıklarına inandıkları değerler açısından farklılaşmaktadırlar. Schwartz (1994), kültürler arasında ortaya çıktığını düşündüğü 45 bireysel değerden söz etmektedir. Schwartz bu kavramsallaştırması sonrasında dünya çapında öğrenci ve öğretmenler ile bir araştırma 
yapmıştır. Veri analizi sonucunda bu 45 değerin 7 bağımsız kültürel boyuta indirgenebileceğini ortaya çıkarmıştır. Schwartz ve Trompenaars, çerçevelerinin çağdaş, teorik açıdan güçlü olmaları, karmaşık ve sistematik örneklem tekniklerini kullanmaları açısından farklı değerlendirilmiştir. Schwartz ve Trompenaars'ın kapsamı (çerçevesi) diğerlerine göre Hofstede ve diğer çalışmalara göre (GLOBE, CD ve ID index vb.), daha çağdaş, teorik olarak güçlü ve kullandığı örneklem teknikleri daha karmaşık ve sistematik olarak değerlendirilmektedir (Magnusson, vd., 2008: 185).

Schwartz'ın değerleri ile Hofstede'in boyutları kıyaslandığında Schwartz'ın boyutları çeşitli avantajlar sunmaktadır:

- Schwartz'ın değerleri teorik bir temele dayanmaktadır.

- Daha kapsamlı değer boyutlarını içermektedir.

- Daha güncel veriler ile test edilmiştir (1988 ve 1992 arasında toplanmıştır) ve iki eşleştirilmiş örneklemden yararlanılmıştır.

- OÖrneklemler daha değişik bölgelerden elde edilmiştir (sosyalist ülkeler de dahil olmak üzere doğu bloğu ülkeleri gibi)

Schwartz'ın, Hofstede'in boyutlarını da içerdiğini savunduğu boyutları, kültürel uzaklığı hesaplamak için bazı çerçevelerde daha uygun olabilecek alternatif bir yol sağlamaktadır. Örneğin, Jackson (2001), Hofsetede'in bireyselcilik boyutunun aşırı basitleştirilmiş olduğunu ve Schwartz'in eşitlikçi yaklaşım boyutunun, bireysel olarak sınıflandırılan ülkelerde etik özellikleri açıklama konusunda daha uygun olabileceğini savunmaktadır. Hofstede çalışmasını amprik olarak, Schwartz ise teorik olarak ortaya koymuştur. Her iki araştırmacı da geniş ölçekli çok ülkeyi içeren örneklem kullanarak çalışmalarını gerçekleştirmişlerdir. Ülkelerin kendi içlerinden çok ülkeler arasında önemli farklılıklar ortaya koymuşlardır (Ng, Lee, Soutar, 2007: 167) Schwartz, bireysellik ve toplumsallık gibi sınıflandırmaya dayalı bir değerlendirmeyi eleştirmektedir. Bunun nedenleri ise: a) doğaları gereği, hem kişisel ihtiyaçlara (bireyselcilik), hem de grup ihtiyaçlarına (toplumculuk) karşılık gelebilecek değerler olabilir. Bu durum, bireysel, ailevi ve ulusal güvenlik arayışı için motivasyonu içeren değerlerde ortaya çıkabilmektedir. b) bu ikililik, toplumcu amaçlara hizmet etmekte ancak gerçekte grup içi özellikleri taşımamaktadır (herkes için eşitlik, sosyal adalet, doğayı koruma gibi). Schwartz’a göre, eğer toplumculuk grup içi fonksiyonu olarak tanımlanırsa grup içi toplumculuk ve evrensel toplumculuk arasında ayrım yapılması gerekmektedir. c) bu ikililik kutup karşıtlığı oluşturmaktadır; birbiriyle çatışma içinde olmayan bireysel ve toplumcu ihtiyaçlar olabilir. Örneğin, hazcılık, özyönelim kişinin ihtiyaçlarına hizmet eden değerlerdir ancak toplumculuğun lehine olmayabilir. Aynı değerler bütün bireylerin amaçları olarak, bir toplumun bireyleri ya da liderleri tarafından yerleştirilebilir (Gouveia ve Ros, 2000: 26).

Hosftede gibi Schwartz da her ne kadar, Hosftede'den farklı bir bakış açısı kullansa da kültürel değerler teorisinde, bireyselcilik ve toplulukçuluk boyutlarını karşılaştırmıştır. Kültürler, kendini yüceltme (egemenlik) ve sosyal değişimi (entelektüel ve etkisel otonomi) destekleyen değer türlerine verdikleri kültürel önem doğrultusunda sınıflandırılabilirler. Egemenliğe önem veren kültürler, kişisel mücadeleye ve azim, başarı, yetenek, risk alma gibi değerlere önem vermektedirler. Diğer taraftan entelektüel ve etkisel otonomi, bireylerin fikir ve düşüncelerine önem vermektedir. Kültürler iki tür toplumculuğa sahip olabilirler: Eşitlikçi taahhüt, muhafazakarlık ve hiyerarşi. Eşitlikçi taahhüde sahip toplumlar üyelerini diğerleri ile gönüllü bir şekilde iş birliğine girecek ve kendi refahlarını düşünecek şekilde sosyal hale getirmektedir. Diğer taraftan muhafazakarlığı savunan toplumlar mevcut durumun korunmasina önem vermektedirler; hiyerarşiye önem veren toplumlar da rollerin hiyerarşik sistemlerine ve güçteki farkl111klara önem vermektedirler (Basabe ve Ros, 2005: 192; Schwartz, 1994; Ros \& Schwartz, 1995). 
$\mathrm{Bu}$ üç kültür modeli birbirleri ile karşılaştırıldıklarında iki önemli konuyu gerçekleştirmeye çalıştıkları görülmektedir. Birincisi, her bir model çeşitli kültürlerin kıyaslanabilecekleri boyutları tanımlamaktadırlar. İkinci olarak, Trompenaars ve Hofstede'in modelleri çeşitli kültürleri değerlendirmek için sayısal sonuçlar ortaya koymaktadırlar. Bu doğrultuda bu üç kültür modeli çalışması kültürel farklılıkları temsil etmenin pek çok farklı yolu olduğunu göstermektedirler. Bu kültürel modeller, sosyal inanışlar, normlar, değerler gibi farklı kültür unsurlarına odaklanmak ile birlikte modeller arasındaki uyumun yeterli düzeyde olmadığ görülmektedir. Uyumun olmaması araştırmacıların çeşitli alanlarda kültürel farklılıkların etkisini araştırmaları konusunda engel teşkil etmektedir. Bir modelin diğeri üzerindeki üstünlüğünü ön plana çıkartmaktan çok kültür modellerinin yönetim uygulamaları konusunda kültür anlayışına yaptıkları katkı göz önünde bulundurulduğunda kültürler arasında temel farklılıkları temsil eden ortak temaların varlığından söz edilebilir (Nardon ve Steers, 2009: 7-8).

1) Toplumda güç ve otoritenin dağılımı: Bir toplumda güç ve otorite nasıl dağıllır? $\mathrm{Bu}$ dağılım hiyerarşi ya da eşitlikçilik kavramlarına göre mi gerçekleşir? Eşitlik ve imtiyazlar konusundaki sosyal inanışlar nedir?

2) Sosyal ilişkiler temelinde bireylerin ve grupların merkeziliği: Bir toplumun temel bloğu nedir: Bireyler ya da gruplar? Toplum eylem için bir toplum nasıl organize olur?

3) Bireylerin çevre ile ilişkileri: Sosyal temelde bireyler çevrelerindeki dünyayı nasıl görmektedirler? Amaçları çevrelerini ve etraflarındaki olayları kontrol etmek midir? Ya da bu dış gerçeklik ile uyumlu bir şekilde yaşamak mıdır?

4) Zamanın kullanımı: Bir toplumda bireyler, iş ile ilgili ve iş dışı faaliyetlerini yerine getirmek için zamanı nasıl organize ederler ve yönetirler? Doğrusal ya da doğrusal olmayan bir düzlemde mi işlerine yaklaşım gösterirler?

5) Kişisel ve sosyal kontrol mekanizmaları: Toplumlar üyelerinin davranışlarındaki tahmin edilebilirliği nasıl sağlamaya çalışırlar? Bireyleri, eşit bir şekilde uygulanan kurallar, politikalar, kanunlar, sosyal normlara vasıtası ile mi kontrol etmeye çalışmakta ya da kişisel bağlara ve kendine özgü durumlara mı daha fazla dayanmaktadırlar?

Aşağıda yer alan tabloda her üç kültür modelinde ortak olarak yer alan konular ele alınmaktadır. Tabloda belirli boyutlar açısından kültür modellerinin karşılaştırılması yapılmış ve birbirlerine göreli olarak üstün ve zayıf yönleri ifade edilmiştir. 
Tablo 1. Kültür Modellerinin Karşılaştırılması

\begin{tabular}{|c|c|c|c|}
\hline & Hostede & $\begin{array}{l}\text { Hampden - Turner ve } \\
\text { Trompenaars }\end{array}$ & Schwartz \\
\hline $\begin{array}{l}\text { Uygulanabilir analiz } \\
\text { düzeyleri }\end{array}$ & $\begin{array}{l}\text { - Ulusal düzeyde analizlerde } \\
\text { açılaylayıı } \\
\text { - Örgütsel ve bireysel düzeyde } \\
\text { yetersiz/basite indirgenmiş }\end{array}$ & $\begin{array}{l}\text { - Farklı analiz } \\
\text { düzeylerinde } \\
\text { uygulanabilir. } \\
\text { - Daha kapsayıcı, düzeyler } \\
\text { arası ilişkileri açıklayıcı. }\end{array}$ & $\begin{array}{l}\text { - Farklı analiz } \\
\text { düzeylerinde } \\
\text { uygulanabilir. } \\
\text { - Karmaşık } \\
\text {-Sosyo-psikolojik düzeyde } \\
\text { analize uygun }\end{array}$ \\
\hline $\begin{array}{l}\text { Değişimi açılama } \\
\text { potansiyeli }\end{array}$ & $\begin{array}{l}\text { - Genel anlamda durağan bir } \\
\text { model. } \\
\text { - Değişimi açıklamakta sınırlı }\end{array}$ & $\begin{array}{l}\text { - Değişimi açılklama } \\
\text { potansiyeli yüksek ancak } \\
\text { bazı boyutlarda sorunlu }\end{array}$ & $\begin{array}{l}\text { - Değişimi açılama } \\
\text { potansiyeli yüksek ancak } \\
\text { uygulama da zorlayıcı }\end{array}$ \\
\hline Ampirik/teorik destek & $\begin{array}{l}\text { - Modelin oluşturulduğu } \\
\text { dönemin verisi güncel kabul } \\
\text { edilmemekte } \\
\text { - Daha sonraki çalışmalarla } \\
\text { birlikte en fazla sinanmış } \\
\text { model / yüksek ampirik destek }\end{array}$ & $\begin{array}{l}\text { - Güçlü teorik alt yapı } \\
\text { - Kismen uygulaması zor } \\
\text { - Ampirik destek zayıf }\end{array}$ & $\begin{array}{l}\text {-Güçlü teorik altyapı } \\
\text {-Uygulaması zor ve } \\
\text { karmaşık }\end{array}$ \\
\hline Analiz teknikleri & $\begin{array}{l}\text { - Nispeten daha basit ancak } \\
\text { uygulama da kolay. } \\
\text { - Yaygınlığı daha geniş }\end{array}$ & $\begin{array}{l}\text { - Karmaşık analiz } \\
\text { teknikleri gerektirmekte }\end{array}$ & $\begin{array}{l}\text {-Sistematik ve güçlü ancak } \\
\text { uygulaması zor }\end{array}$ \\
\hline
\end{tabular}

Kaynak: Yazar tarafindan oluşturulmuştur.

Tablo 1'den anlaşıldığı üzere farklı kültür modellerinin farklı güçlü ve zayıf yanları mevcuttur. Yapılacak araştırmanın araştırma soruları veya geliştirilecek/geliştirilmesi düşünülen kuramsal katkıya uygun olarak kültür çalışmalarında modeller tercih edilebilir. Örneğin Hofstede'in kültür modelinin yoğun bir amprik desteği mevcutken araştırmacıları teorik kısıtları nedeni ile zorlayabilir. Benzer şekilde Schwartz modelini çeşitli düzeylerde analize uygun ve daha güçlü bir teorik altyapı ile geliştirmişken saha sırasında sınanması daha zor bir modeldir. Benzer şekilde Hampden - Turner ve Trompenaars'ın modeli de ampirik verilerin analizinde daha karmaşık yöntemlerin kullanılmasını gerektirebilir.

\section{SONUÇ}

$\mathrm{Bu}$ çalışmada amaç, Hofstede, Hampden - Turner ve Trompenaars ve Schwartz tarafindan kültürleri sınıflandırmak üzere ortaya koyulan modellerin, bu modeller içerisinde yer alan boyutların değerlendirilmesi ve içerik, yöntem ve sonuçlar açısından karşılaştırmalarının yapılmasıdır. Bu sayede kültür çalışmalarında bulunanlara modellerin güçlü ve zayıf yanları tanıtılarak yapılacak katkının potansiyelini artırmak istenmektedir.

Her üç kültür modeli, kültürlerin birbirleri ile karşılaştırılabilecekleri boyutları ortaya koymuştur. Ancak bu kültür modelleri tarafindan ortaya koyulan farklı boyutları içeren yaklaşımlar elde edilen sonuçların karşılaştırılmasını güçleştirmekte ve kültürel farklılıklar konusunda yapılan araştırmaların gelişimini engellemektedir. Ulusal kültür araştırmalarında elde edilecek ortak noktalar ise, kullanılabilirliklerini ve muhtemel geçerliliklerini etkilemekte ve farklılıklar üzerine odaklanan küresel işletme stratejilerinin oluşumuna yönelik anlayışları olumlu yönde etkilemektedir. 
$\mathrm{Bu}$ kültür boyutları incelendiğinde her ne kadar birbirleri ile ortak temalara sahip oldukları ve özellikle Hofstede ve Trompenaars'ın araştırmaları sonucunda elde ettikleri sayısal değerler açısından ülkeler için birbirine yakın birtakım sınıflandırmalara ulaştıkları görülse de pek çok açıdan farklı özellikler taşımaktadırlar. Araştırmaların gerçekleştiği zaman sürecinin farklı olması, ele aldıkları boyutların ve örneklem metotlarının karmaşıklığı, günümüz dünyasını aç1klayabilme açısından yeterlilikleri, farklı analiz düzeylerine ve farklı araştırma metotlarına uygulanabilirlikleri gibi açılardan değerlendirildiğinde farklılaşan yönlerinin daha fazla olduğu görülmektedir.

Her üç kültür modeli için geçerli olan diğer önemli konular ise, kültürleri sınıflandırmak için oluşturulan taksonomilerin, ulusal kültürlerin bu tarz sınıflandırmalar ile açıklanamayacak kadar karmaşık yapılar olmaları nedeni ile yetersiz kaldıklarıdır. Bu tarz ayrımların araştırma yöntemi açısından halen pozitivizmin etkisinde kaldığg görülmektedir. Farklı ülkelerdeki kültürel özelliklerin ve farklılıkların, bu farklılıkları değerlendirecek boyutların ortaya çıkarılması amaçlansa da, bu araştırmaların çeşitli kültürel analizler, örneğin aynı ülke içerisinde farklı bölgelerin analizini ortaya koymada yetersiz kalacakları sonucuna ulaşılmaktadır. Kültür gibi çok boyutlu ve karmaşık bir konunun analizi için kültürün içerden analizinin, diğer bir ifade ile emik yaklaşımların ön plana çıkması gerektiği düşünülmektedir.

Kültürel farklılıkların birey, ulus düzeyinde düşünüldüğünde içerdikleri karmaşık unsurlar nedeni ile kolay yönetilemediği de göz önünde bulundurularak, bu sınıflandırmaların bir ölçüde ötekileştirmeye ve kültürel farkl1lıkları değerlendirme açısından bir genelleştirmeye hizmet ettiği sonucuna varılmaktadır.

Çalışmada görülmüştür ki, doğası gereği girift bir yapıda olan kültürü açıklamak istendiğinde fenomeni basitleştirmek isteyen çalışmalar kısmen açıklamayı başarmışlardır. Alanda en fazla kullanılan model olan Hofstede'in teorik olarak daha güçlü hale getirilmesi için açıklayıcılığının artırılması gerekmektedir. Modelin en zayıf noktası fazla genel geçer olmasıdır. $\mathrm{Bu}$ durum bu modelle ilgili çalışmaların daha farklı yöntemlerle ve analiz teknikleri ile yeniden sınanmasını gerektiğini göstermektedir.

Diğer iki modelin güçlü teorik altyapısı olması ve farklı analiz düzeylerini açılayabilme potansiyelinin yüksek olması olumlu bir yan olarak düşünülebilir. Ancak uygulamada Hofstede'in modeli kadar başarılı olmamaları, doğru şekilde yapılacak ölçme tekniklerinin karmaşık olması modellerin zayıf yanları arasında yer almakta ve pratik yönlerini zedelemektedir.

\section{Araştırma ve Yayın Etiği Beyanı}

Bu çalışma bilimsel araştırma ve yayın etiği kurallarına uygun olarak hazırlanmıştır.

\section{Yazarların Makaleye Katkı Oranları}

Çalışmada yazarın katkısı \%100'dür.

\section{Çıkar Beyanı}

Yazarlar açısından ya da üçüncü taraflar açısından çalışmadan kaynaklı çıkar çatışması bulunmamaktadır. 


\section{KAYNAKÇA}

Basabe, N., \& Ros, M. (2005). Cultural dimensions and social behavior correlates: Individualism-Collectivism and Power Distance. International Review of Social Psychology, 18(1), 189-225.

Bhaskaran, S., \& Sukumaran, N. (2007). National culture, business culture and management practices: consequential relationships?. Cross Cultural Management: An International Journal.

Brewer, P., \& Venaik, S. (2012). On the misuse of national culture dimensions. International Marketing Review.

Chanchani, S., \& Theivananthampillai, P. (2009). Typologies of culture. Available at SSRN 1441609.

Gooderham, P. N., \& Nordhaug, O. (2003). International management: cross-boundary challenges. Blackwell.

Gouveia, V. V., \& Ros, M. (2000). Hofstede and Schwartz s models for classifying individualism at the cultural level: their relation to macro-social and macro-economic variables. Psicothema, 12(Su1), 25-33.

Hall, E. T. (1959). The silent language. NY. Y.: Doubleday, 240.

Herskovits, M. J. (1949). Man and his works; the science of cultural anthropology. Alfred A. Knopf.

Hofstede, G. (1980). Culture and organizations. International studies of management \& organization, 10(4), 15-41.

Hofstede, G. (2001). Culture's consequences: Comparing values, behaviors, institutions and organizations across nations. Sage publications.

Hofstede, G. (2003). Cultural dimensions. www.geert-hofstede.com.

Hofstede, G. (2011). Dimensionalizing cultures: The Hofstede model in context. Online readings in psychology and culture, 2(1), 2307-0919.

Hofstede, G. J., Jonker, C. M., \& Verwaart, T. (2008). Long-term orientation in trade. In Complexity and Artificial Markets (pp. 107-119). Springer, Berlin, Heidelberg.

Hoft, N. (1999). Global issues, local concerns. Technical communication, 46(2), 145.

Jacob, N. (2005). Cross-cultural investigations: emerging concepts. Journal of Organizational Change Management.

Kagitcibasi, C. (1997). Individualism and collectivism. Handbook of cross-cultural psychology, 3, 1-49.

Kagitcibasi, C., \& Berry, J. W. (1989). Cross-cultural psychology: Current research and trends. Annual review of psychology, 40(1), 493-531.

Kluckhohn, F. R., \& Strodtbeck, F. L. (1961). Variations in value orientations. Row, Peterson.

Laurent, A. (1983). The cultural diversity of western conceptions of management. International Studies of Management \& Organization, 13(1-2), 75-96.

Lew1s, R. D. (2006), When Cultures Collide: Managing Successfully Across Cultures, Nicholas Brealey Publishing, Boston.

López-Duarte, C., Vidal-Suárez, M. M., \& González-Díaz, B. (2016). International business and national culture: A literature review and research agenda. International Journal of Management Reviews, 18(4), 397-416.

Magnusson, P., Wilson, R. T., Zdravkovic, S., Zhou, J. X., \& Westjohn, S. A. (2008). Breaking through the cultural clutter: A comparative assessment of multiple cultural and institutional frameworks. International Marketing Review.

Morden, T. (1999). Models of national culture-a management review. Cross Cultural Management: An International Journal.

Nardon, L., \& Steers, R. M. (2009). The culture theory jungle: Divergence and convergence in models of national culture. Cambridge handbook of culture, organizations, and work, 3-22.

Ng, S. I., Lee, J. A., \& Soutar, G. N. (2007). Tourists' intention to visit a country: The impact of cultural distance. Tourism management, 28(6), 1497-1506.

Ronen, S., \& Shenkar, O. (1985). Clustering countries on attitudinal dimensions: A review and synthesis. Academy of management Review, 10(3), 435-454.

Schein, E. H. (1985). Defining organizational culture. Classics of organization theory, 3(1), 490-502.

Schwartz, S. H. (1994). Beyond individualism/collectivism: New cultural dimensions of values.

Schwartz, S. H. (2012). An overview of the Schwartz theory of basic values. Online readings in Psychology and Culture, 2(1), 2307-0919. 
Sığrı, Ü., Tabak, A., \& Ercan, Ü. (2009). Kültürel değerlerin yönetsel kapsamda analizi: Türk bankacılık sektörü uygulaması. Organizasyon ve yönetim bilimleri dergisi, 1(2), 1-14.

Soares, A. M., Farhangmehr, M., \& Shoham, A. (2007). Hofstede's dimensions of culture in international marketing studies. Journal of business research, 60(3), 277-284.

Trompenaars, F. (1996). Resolving international conflict: Culture and business strategy. Business strategy review, 7(3), 51-68.

Trompenaars, F., \& Hampden-Turner, C. (1995). The seven cultures of capitalism: Value systems for creating wealth in Britain, the United States, Germany, France, Japan, Sweden and the Netherlands. London: Judy Piatkus Publishers Ltd.

https://globeproject.com/

https://www.worldvaluessurvey.org/wvs.jsp

https://www.hofstede-insights.com/ 


\section{Extended Summary}

\section{Comparison of National Cultural Models Used in Management Studies}

Values are important cultural dimensions that hold the members of a nation together and shape their perspective on values in other cultures. It is important to examine the differences in national cultures in terms of revealing the attitudes of individuals towards different cultures. The fact that globalization continues to affect countries, societies, organizations, and people around the world in terms of economic, socio-cultural, political, and technological aspects have made a research on differences in national cultures even more important. In this study, the aim is to examine in depth the cultural models put forward by Hofstede, Hampden-Turner and Trompenaars and Schwartz, which are prominent among the national culture model theories. The examination of the models and the criticisms were made by making comparisons of three different cultural models. In this way, it is desired to create a theoretical thinking area for the studies carried out to understand the national differences and similarities, which have gained importance in recent years, especially in management studies.

The first of these models is Hofstede's cultural values model. Dutch management researcher Geert Hofstede $(1980,2001)$ developed the most widely used model of cultural differences in the organizational literature. Hofstede's model emerged as a result of a study of employees of a large multinational company from various countries, and this study is based on the fact that different cultures can be distinguished according to their differences in what they value. Some cultures place great emphasis on equality between individuals, while others emphasize hierarchy and power distance between individuals. Similarly, some cultures value certainty in their daily lives and have difficulty coping with unexpected events, while others have a great tolerance for uncertainty and enjoy change.

The second model under consideration is the study of Hampden - Turner \& Trompenaars called The Seven Cultures of Capitalism. Trompenaars (1996) used the metaphor of layers of an onion to describe culture. The outer layer is what people associate with culture: observable facts like language, food, clothing. The middle layer refers to the norms and values that a community has. What is defined as right or wrong, good or bad? Understanding the innermost layer is the key to working successfully with other cultures. It includes a series of rules and methods developed to deal with the ongoing problems that society faces. Charles Hampden-Turner introduced culture as a way of solving dilemmas arising from universal problems. Reconciliation of these dilemmas forms the basis of strategy formulation (Trompenaars, 1996: 52). They revealed that cultural preferences and values are the cornerstones of national identity and the source of economic strengths and weaknesses.

The third model is Schwartz's Value Theory. Schwartz et al. have argued that the main difference between a psychological perspective and social values is the motivational goals they express. They identified 10 universal human values that reflect needs, social motives, and social institutional demands. These values are found in all cultures and represent the universal needs of human existence. Mentioned values are power, achievement, hedonism, stimulation, selfdirection, universality, benevolence, tradition, conformity, security. Schwartz (1994) argues that individual and cultural analysis levels are independent. The dimensions at the individual level reflect the psychological dimensions that they experience while acting according to their values in daily life, and the dimensions at the cultural level reflect the solutions that societies find to regulate the activities of individuals. In his cultural level analysis, Schwartz identified three dimensions. These dimensions are conservatism - autonomy, hierarchy - egalitarianism, sovereignty - harmony. Schwartz's model has been applied to fundamental areas of social behavior, but its application in organizational studies has been limited. 
Table 1. Comparison of three models

\begin{tabular}{|c|c|c|c|}
\hline & Hostede & $\begin{array}{l}\text { Hampden - Turner ve } \\
\text { Trompenaars }\end{array}$ & Schwartz \\
\hline $\begin{array}{l}\text { Applicable analysis } \\
\text { levels }\end{array}$ & $\begin{array}{l}\text { - Descriptive in national level } \\
\text { analyzes } \\
\text { - Inadequate/simplified at an } \\
\text { organizational and individual } \\
\text { level }\end{array}$ & $\begin{array}{l}\text { - It can be applied at } \\
\text { different analysis levels. } \\
\text { - More inclusive, } \\
\text { descriptive of inter-level } \\
\text { relations. }\end{array}$ & $\begin{array}{l}\text { - It can be applied at } \\
\text { different analysis levels. } \\
\text { - Complicated } \\
\text {-Appropriate for analysis } \\
\text { at a socio-psychological } \\
\text { level }\end{array}$ \\
\hline $\begin{array}{l}\text { The potential to } \\
\text { explain the change }\end{array}$ & $\begin{array}{l}\text { - Generally a stable model. } \\
\text { - Limited in explaining change }\end{array}$ & $\begin{array}{l}\text { - High potential to explain } \\
\text { the change, but } \\
\text { problematic in some } \\
\text { dimensions }\end{array}$ & $\begin{array}{l}\text { - High potential to explain } \\
\text { the change, but } \\
\text { challenging to implement }\end{array}$ \\
\hline $\begin{array}{l}\text { Empirical/theoretical } \\
\text { background }\end{array}$ & $\begin{array}{l}\text { - The data of the period in } \\
\text { which the model was created is } \\
\text { not considered up-to-date. } \\
\text { - Most tested model with } \\
\text { further studies / high empirical } \\
\text { support }\end{array}$ & $\begin{array}{l}\text { - Strong theoretical } \\
\text { background } \\
\text { - Partially difficult to } \\
\text { implement } \\
\text { - Empirical support is } \\
\text { weak }\end{array}$ & $\begin{array}{l}\text { - Strong theoretical } \\
\text { background } \\
\text { - Difficult and complex to } \\
\text { implement }\end{array}$ \\
\hline Analysis techniques & $\begin{array}{l}\text { - It is relatively primitive but } \\
\text { also easy to implement. } \\
\text { - Widespread application }\end{array}$ & $\begin{array}{l}\text { - Requires complex } \\
\text { analysis techniques }\end{array}$ & $\begin{array}{l}\text {-Systematic and powerful } \\
\text { but difficult to implement }\end{array}$ \\
\hline
\end{tabular}

As a result, all three culture models revealed the dimensions in which cultures can be compared with each other. However, approaches involving different dimensions introduced by these cultural models make it difficult to compare the results obtained and hinder the development of research on cultural differences. Commonalities in national culture studies affect their usability and possible validity, and positively influence understandings of the formation of global business strategies that focus on diversity.

When these cultural dimensions are examined, although it is seen that they have common themes with each other and they have reached some classifications close to each other in terms of the numerical values they obtained as a result of the researches of Hofstede and Trompenaars, they have different characteristics in many respects. When the researches are evaluated in terms of different periods, the complexity of the dimensions and sampling methods they deal with, their adequacy in terms of explaining today's world, their applicability to different analysis levels and different research methods, it is seen that they differ more.

Other important issues valid for all three culture models are that the taxonomies created to classify cultures are insufficient because national cultures are too complex to be classified with such taxonomies. It is seen that such distinctions are still under the influence of positivism in terms of research methods. Although it is aimed to reveal the cultural characteristics and differences in different countries and the dimensions that will evaluate these differences, it is concluded that these studies will be insufficient to reveal various cultural analyzes. For the analysis of a multidimensional and complex subject such as culture, it is thought that the analysis of culture from within, in other words, emic approaches should come to the fore.

Considering that cultural differences cannot be easily managed due to the complex elements they contain, it is concluded that these classifications serve to marginalize to some extent and to generalize in terms of evaluating cultural differences. 
When it is desired to explain the culture, which is an intricate structure by nature, studies that want to simplify the phenomenon have partially succeeded in explaining it. Hofstede, which is the most used model in the literature, needs to be increased to make it theoretically stronger. The weakest point of the model is that it is too general and simple. This shows that studies on this model should be retested with different methods and analysis techniques.

It can be considered as a positive side that the other two models have a strong theoretical background and have a high potential to explain different levels of analysis. However, they are not as successful as Hofstede's model in practice, and the complexity of measuring techniques to be done correctly is among the weaknesses of the models and damage their practical aspects. 
Optimum Journal of Economics and Management Sciences, Vo1. 9, No. 1- https://dergipark.org.tr/tr/pub/optimum Dirlik - Comparison of National Cultural Models Used in Management Studies 